\title{
Polylactide (PLA)-based amphiphilic block copolymers: synthesis, self-assembly, and biomedical applications
}

\author{
Jung Kwon Oh* \\ Received 23rd December 2010, Accepted 24th February 2011 \\ DOI: 10.1039/c0sm01539c
}

Polylactide (PLA) and its copolymers are one type of hydrophobic aliphatic polyester based on hydroxyalkanoic acids. They possess exceptional qualities: biocompatibility; FDA approval for clinical use; biodegradability by enzyme and hydrolysis under physiological conditions; low immunogenicity; and good mechanical properties. These critical properties have facilitated their value as sutures, implants for bone fixation, drug delivery vehicles, and tissue engineering scaffolds in pharmaceutical and biomedical applications. However, the hydrophobicity of PLA and its copolymers remains concerns for further biological and biomedical applications. One promising approach is to design and synthesize well-controlled PLA-based amphiphilic block copolymers (ABPs); typical hydrophilic copolymers include poly(meth)acrylates, poly(ethylene glycol), polypeptides, polysaccharides, and polyurethanes. This review summarizes recent advances in the synthesis and self-assembly of PLA-containing ABPs and their bio-related applications including drug delivery and imaging platforms of self-assembled nanoparticles, and tissue engineering of crosslinked hydrogels.

\section{Introduction}

Hydrophobic aliphatic polyesters based on hydroxyalkanoic acids, such as polylactide (PLA), polycaprolactone (PCL), and polyglycolide (PGA) are important synthetic biomaterials. These

Department of Chemistry and Biochemistry, Concordia University, 7141 Sherbrooke St.W., Montreal, Quebec, Canada H4B 1R6.E-mail: joh@, alcor.concordia.ca; Tel: +1-514-848-2424 ext. 5306

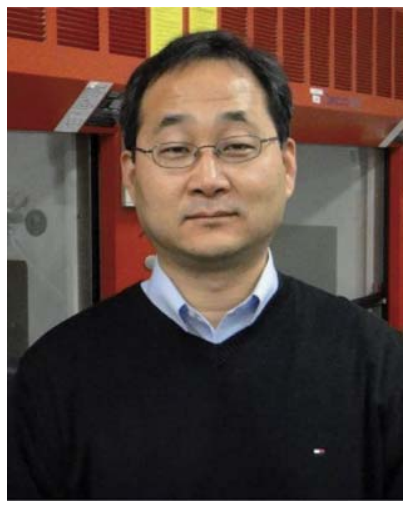

Jung Kwon Oh
Jung Kwon Oh is a Tier II Canada Research Chair in Nanobioscience and an Assistant Professor in the Department of Chemistry and Biochemistry at Concordia University in Montreal, Canada. He earned his PhD degree from the University of Toronto and then completed his postdoctoral research at Carnegie Mellon University. He has been employed at Dow Chemical Company. His research has been recognized with several prestigious awards including the NSERC Postdoctoral Fellowship of Canada in 2004 and the PCI Outstanding Paper Award in 2010. His research interests involve the design and processing of macromolecular nanoscale materials for biomedical applications. copolymers are biocompatible, FDA-approved for a clinical use, and biodegradable by enzyme and hydrolysis under physiological conditions. They also have low immunogenicity and good mechanical properties. These unique properties have facilitated their use in pharmaceutical and biomedical applications as sutures, implants for bone fixation, drug delivery vehicles, and tissue engineering scaffolds. ${ }^{1-4}$ PLA and its copolymers are generally synthesized by ring opening polymerization (ROP) of LA and copolymerization with other cyclic monomers, initiated with hydroxyl- and amine-functionalized initiators. Examples of the typical cyclic monomers include mainly GA for PLGA, ${ }^{5-10}$ $\mathrm{CL}$ for $\mathrm{P}(\mathrm{LA}-\mathrm{co}-\mathrm{CL}),{ }^{11}$ a cyclic carbonate monomer for P(LA-co-carbonate), ${ }^{12}$ dipropargyl glycolide (DPGA) for P(LA-co-DPGA), ${ }^{13}$ and allyl glycidyl ether (AGE) for PLA- $b$-PAGE. ${ }^{14,15}$ Recently, the synthesis of functional polyesters including PLA has been reviewed. ${ }^{16,17}$ PLA exists as three types of stereoisomers; optically active poly(L- $(-)-S$-lactide) (PLLA) and poly(D-(+)-R-lactide) (PDLA), and racemic PDLLA. Stereoisomeric mixtures of PLLA/PDLA form stereocomplexes through physical association of PLLA and PDLA chains with distinctive physical and chemical stability and enhanced mechanical strength. ${ }^{18}$

For successful biological and biomedical applications of PLA and its copolymers, one serious challenge is associated with their hydrophobicity. For hydrophobic drug delivery applications, as an example, the hydrophobicity of PLA and its copolymers enhances the uptake of drug-loaded nanoparticles (NPs) through mononuclear phagocyte system (MPS), resulting in their short residence time in circulation. This consequently causes a decrease in drug efficiency in vivo. One promising approach to achieving 
long circulation of hydrophobic PLA-based NPs in the blood is to coat their surface with hydrophilic polymers. This approach has been facilitated by preparation of well-controlled PLAcontaining amphiphilic block copolymers (ABPs) for drug delivery applications. These ABPs self-assemble in water toward the formation of core/shell micellar NPs; a hydrophobic core is capable of carrying a variety of hydrophobic therapeutic agents and hydrophilic coronas ensure water-solubility and biocompatibility of the NPs. ${ }^{19}$ In addition, PLA-based ABPs have been explored for the development of other biomaterials, including crosslinked hydrogels as tissue engineering scaffolds and selfassembled metal hybrid nanomaterials as imaging platforms. Another challenge is to engineer PLA-based ABPs capable of bioconjugation with ligand biomolecules for targeting specific cells as well as promoting biocompatibility with living cells. This has been achieved by designing functional PLA-based ABPs. The functional groups that have been exploited include carboxylic acid $(-\mathrm{COOH})$, amino $\left(-\mathrm{NH}_{2}\right)$, and hydroxyl $(-\mathrm{OH})$ groups, which are utilized for bioconjugation with targeting biomolecules to achieve active targeting of specific cells.

This review describes recent advances in the synthesis and biomedical application of PLA-based biomaterials. Since these materials are built with ABPs through self-assembly, this review begins with the preparation and self-assembly of PLA-based ABPs using a hydrophilic block; typical hydrophilic copolymers include poly(meth)acrylates, poly(ethylene glycol) (PEG), polypeptides, polysaccharides, and polyurethanes. These copolymers are either naturally occurring or mainly synthesized by radical, ring opening, or condensation polymerization methods. Further, this review summarizes biological and biomedical applications of these PLA-based ABPs, including biological evaluations - cytotoxicity and viability, drug delivery and imaging platforms of self-assembled NPs, and tissue engineering of crosslinked hydrogels.

\section{Preparation and self-assembly of PLA-based amphiphilic block copolymers}

A variety of methods to synthesize well-defined PLA-based ABPs with hydrophilic polymers have been explored. Typical examples of hydrophilic polymers include poly(meth)acrylates, PEG, polypeptides, polysaccharides, and polyurethanes. These ABPs self-assemble to form micellar core/shell NPs.

\subsection{Hydrophilic poly(meth)acrylates}

A general method to prepare PLA-based ABPs comprising hydrophilic poly(meth)acrylates involves controlled radical polymerization (CRP) ${ }^{20,21}$ of hydrophilic (or water-soluble) monomers from hydrophobic PLA. In contrast to conventional free radical polymerization, CRP methods adopt the mechanism based on a rapid dynamic equilibration between a minute amount of growing radicals and a large majority of dormant species. Consequently, all polymeric chains grow simultaneously, leading to uniform distribution of molecular weights. These methods enable the synthesis of well-defined (co)polymers with narrow molecular weight distribution $\left(M_{\mathrm{w}} / M_{\mathrm{n}}<1.5\right)$, various chain architectures (block, gradient, graft, hyperbranched, and star), and facile functionalities. Examples of successful CRP methods include atom transfer radical polymerization $(\mathrm{ATRP})^{22,23}$ and reversible addition-fragmentation chain transfer (RAFT) polymerization. ${ }^{24,25}$ Fig. 1 shows the structures of hydrophilic monomers examined for the synthesis of PLA-based ABPs in the literature.

The ATRP has been extensively explored for chain extension of PLA with hydrophilic polymers because of its facile applicability to the synthesis of well-controlled PLA-containing ABPs. A prototype approach involves three synthetic steps (Fig. 2a): (1) ROP of LA to form PLA-OH, (2) conversion of PLA-OH to the corresponding PLA-Br (ATRP macroinitiator), and (3) ATRP of hydrophilic monomers in the presence of PLA-Br. An example includes the synthesis of PLA- $b$-poly(2-methacryloyloxyethyl phosphorylcholine) (PMPC). PMPC is known to suppress protein adsorption and platelet adhesion and thus PMPC-based materials have been developed for biomedical applications. ${ }^{26,27}$ The first step was the synthesis of PLA-OH by the ROP of LA initiated by benzoyl alcohol. The second step was the synthesis of PLA-Br by reaction of PLA-OH with 2-bromo2-methylpropionyl bromide (BMPB). The last step was the ATRP of MPC in the presence of PLA-Br, mediated with $\operatorname{CuBr}(\mathrm{I}) / 2,2^{\prime}$-bipyridine (bpy) catalysts. The structure of the resulting PLA- $b$-PMPC was characterized with composition by NMR and FT-IR spectroscopy, molecular weight by gel permeation chromatography (GPC), and critical micellar concentration (CMC) by fluorescence spectroscopy. Then, the resulting PLA- $b$-PMPC self-assembled in a mixed solvent of EtOH/DMSO using a solvent evaporation method to form stable core/shell NPs comprising PLA core surrounded with PMPC coronas. Their particle size was determined by dynamic light

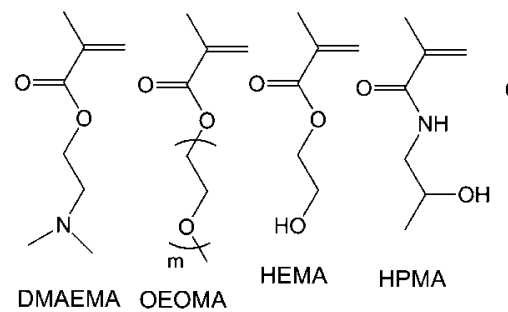

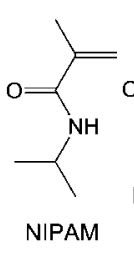

NIPAM
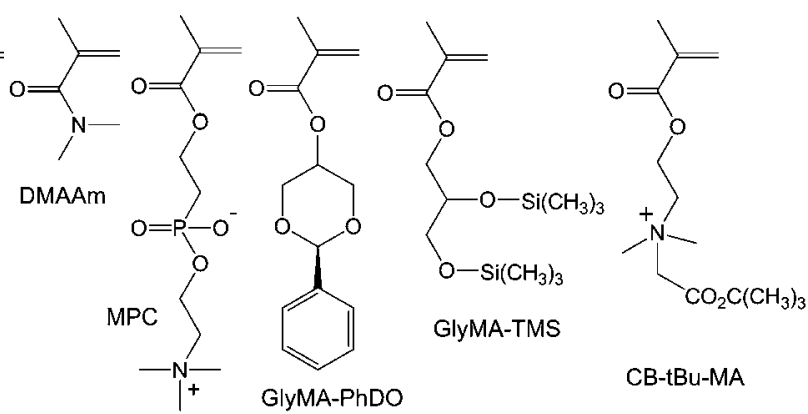

GlyMA-TMS

CB-tBu-MA

Fig. 1 Chemical structure of hydrophilic (meth)acrylate monomers examined for the synthesis of PLA-based ABPs. 
(a)<smiles>CC(C)C(=O)OC(C)(C)c1ccccc1C(=O)OC(C)(C)C(C)O</smiles>

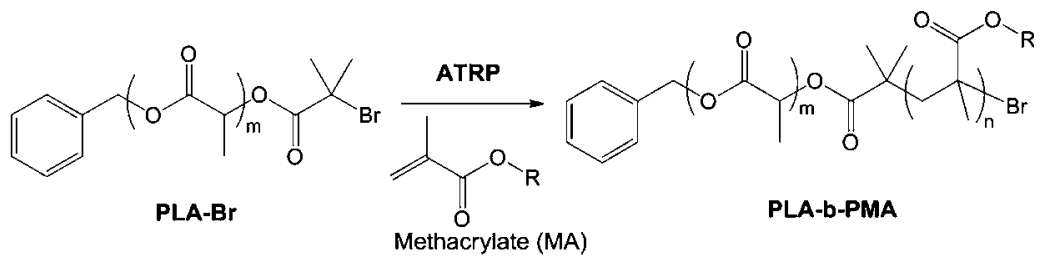

(b)<smiles>CC(C)(Br)C(=O)OCCO</smiles><smiles>CC1OC(=O)C(C)OC1=O</smiles><smiles>CC(C)(COC(=O)C(C)(C)O)COC(=O)C(C)(C)Br</smiles><smiles>[R]OC(=O)C(=C)CCCCC</smiles><smiles>[R]OC(=O)C(CC)(CC(C)(C)C(=O)OCC(C)(C)OC(=O)C(C)O)C(=O)OCC(C)(C)O</smiles>

PLA-b-PMA

Fig. 2 Approach I involving (1) ROP, (2) conversion to PLA-Br, and (3) ATRP (a) and Approach II involving the use of 2-hydroxyethyl-2-bromoisobutyrate (HO-EBiB) (b).

scattering technique to be $100-160 \mathrm{~nm}$ in diameter. Their diameter increased from 118 to $156 \mathrm{~nm}$ as the degree of polymerization of PMPC block increased from 67 to 150. Their biological properties were tested with cytotoxicity to be $>85 \%$, suggesting they are biocompatible up to the concentration of $1 \mathrm{mg} \mathrm{mL}{ }^{-1} .^{28}$ PLA- $b$-poly $(N, N$-dimethylaminoethyl methacrylate) (PDMAEMA) was synthesized for self-assembly, encapsulation, and $\mathrm{pH}$-responsive release of dipyridamole, a hydrophobic drug. ${ }^{29}$ A pair of PLLA- $b$-PDMAEMA (L-stereo form) and PDLA-b-PDMAEMA (D-stereo form) was investigated for stereocomplex formation in water. The resulting stereocomplexes exhibited diffraction patterns assigned to stereocomplex crystallites; their melting point was $65^{\circ} \mathrm{C}$ higher than that of individual copolymers. ${ }^{30}$ Similar approach was also adopted to synthesize PCL-based ABPs. An example includes PEO- $b$-PCL- $b$-PDMAEMA for gene-delivery applications. ${ }^{31}$ However, this prototype approach requires the conversion of PLA-OH to PLA-Br ATRP macroinitiator.

Another approach involves the use of 2-hydroxyethyl-2-bromoisobutyrate (HO-EBiB) as an initiator for both ROP and ATRP: its OH group for the ROP of LA and its bromo group for the ATRP of hydrophilic monomers (Fig. 2b). This approach can be achieved in a rapid one-pot route without purification of PLA- $\mathrm{Br}$ intermediates or in a two-pot route. ${ }^{32}$ Well-controlled PLA-b-poly(2-hydroxyethyl methacrylate) (PHEMA) with $M_{\mathrm{w}} / M_{\mathrm{n}}=1.2-1.3$ was synthesized and characterized using GPC and ${ }^{1} \mathrm{H}-\mathrm{NMR} .{ }^{33}$ PLA- $b$-poly(oligo(ethylene glycol) methacrylate) functionalized with pendent sugar residues was prepared to investigate the molecular recognition of lectin through carbohydrate-protein specific interactions. ${ }^{34}$ PLA- $b$-poly(glycerol monomethacrylate) (PGlyMA) was prepared. ${ }^{35,36}$ Several reports describe the successful ATRP of GlyMA in aqueous or protic solvents. ${ }^{35,37}$ For the synthesis of PLA- $b$-PGlyMA, however, PLA was not dissolved in protic media; consequently, PGlyMA block was generated by the hydrolysis of pendent protected groups from the parent polymers, such as silyl groups from poly(2,3-bistrimethylsilyloxypropyl methacrylate) (P(GlyMATMS $)^{38}$ and acetal groups from poly(2-phenyl-1,3-dioxan-5ylmethacrylate) (P(GlyMA-PhDO) ${ }^{39}$

A zwitterionic block copolymer based on PLGA was synthesized by ATRP of 2-tert-butoxy- $N$-(2-(methacryloyloxy)ethyl)- $N, N$-dimethyl-2-oxoethanaminium (CB- $t \mathrm{Bu}-\mathrm{MA})$ in the presence of 2-aminoethyl-2-bromoisobutyrate, followed by a carbodiimide coupling reaction with PLGA. The resulting PLGA- $b$-P(CB- $t$ Bu-MA) was hydrolyzed to convert tert-butyl ester groups to the corresponding carboxylic acid groups in the presence of trifluoroacetic acid, yielding PLGA- $b$-P(CB-MA) zwitterionic block copolymers. This approach centers on the design of CB side chain having one carboxylic acid that can be used for conjugation with amine-containing biomolecules. Since each carboxylic acid in pendent CB is paired with one cationic quaternary amine as a zwitterionic unit, this pairing exhibited improvement of nonspecific protein absorption (Fig. 3). PLGA$\mathrm{P}(\mathrm{CB}-\mathrm{MA})$ self-assembled in the presence of docetaxel, yielding 1 $\mathrm{wt} \%$ docetaxel-encapsulated NPs with a diameter of $139 \mathrm{~nm}$. The drug release experiments indicate the sustained releasing profile of docetaxel over $96 \mathrm{~h}$ for both $\mathrm{P}(\mathrm{CB}-\mathrm{MA})$-modified and unmodified NPs. In order to investigate cell uptake, these NPs were then modified with galactose to form galactose-modified NPs. A green fluorescent dye called NBD ( $N$-(7-nitro-benz-2oxa-1,3-dizaol-4-yl) was encapsulated as a fluorescent label. NBD-loaded PLGA-P(CB-MA) NPs were incubated with 

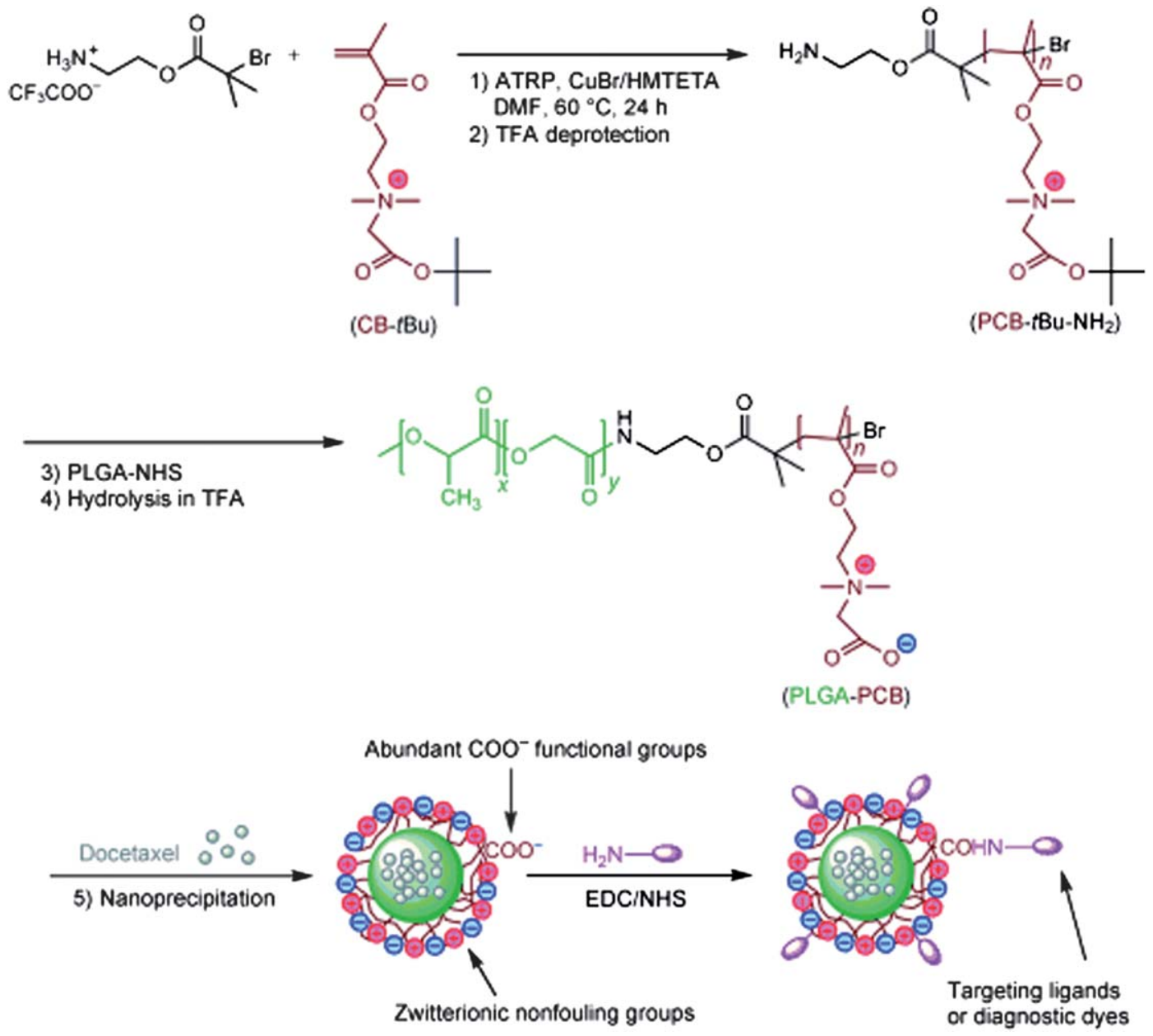

Fig. 3 Synthesis of PLGA-P(CB-MA) copolymers, formation of PLGA-PCB NPs encapsulated with docetaxel, and modification of NPs with targeting ligands. $\mathrm{DMF}=N, N$-dimethylformamide, $\mathrm{HMTETA}=1,1,4,7,10,10$-hexamethyltriethylenetetramine, $\mathrm{TFA}=$ trifluoroacetic acid..$^{40}$ Copyright 2010 Wiley InterScience.

HepG2 cells. It was found that galactose-modified NPs were bound to cells, producing strong fluorescence, while NPs without immobilized ligands resulted in nonspecific targeting, showing low cell binding ability. ${ }^{40}$

RAFT polymerization has also been explored for the preparation of PLA-based ABPs; however, the selection of functional RAFT agents is somewhat limited. A typical approach is the use of OH-functionalized RAFT agents as initiators for both ROP and RAFT polymerization (Fig. 4). 2-[N(2-Hydroxyethyl)carbamoyl]prop-2-yl dithiobenzoate (HECPD) was synthesized and utilized for the synthesis of thermoresponsive $\quad \mathrm{PLA}-\mathrm{b}$-poly $(N$-isopropylacrylamide- $c o-N, N$ dimethylacrylamide) (P(NIPAM-co-DMAm)). Terminal dithio groups were converted to the corresponding thiols by aminolysis, which were used for conjugation with fluorescent dyes. It was observed that intercellular uptake of thermoresponsive micelles formed from P(NIPAM-co-DMAm) was significantly increased at temperatures above the low critical solution temperature (LCST). ${ }^{\mathbf{4 1 , 4 2}} \quad$ Similarly, $\quad$ 2-(benylsulfanylthiocarbonylsulfanyl)ethanol (BSTSE) was utilized to prepare PLGA- $b$ $\mathrm{P}$ (oligo(ethylene oxide) monomethyl ether methacrylate) (POEOMA). The self-assembled micelles were characterized using dynamic light scattering and cytotoxicity of $3 \mathrm{~T} 3$ fibroblast cells. ${ }^{43}$ Recently, a new route towards the synthesis of functional PLA- $b$-poly( $N$-(2-hydroxypropyl)methacrylamide) (PHPMA) was proposed. The synthesis relies on a combination of ROP of LA and conversion into a chain transfer agent for the RAFT polymerization of pentafluorophenyl methacrylate (PFMA). 4-Cyano-4-((thiobenzoyl)sulfanyl) pentatonic acid (CTA) first reacted with the $\mathrm{OH}$ group of PLA to form PLA-functionalized macro-RAFT agent. This agent was then used to mediate the RAFT polymerization of PFMA for PLA- $b$-PPFMA preparation. The pendent pentafluoro groups were then substituted with Oregon Green 488, a fluorescent dye and hydroxypropylamine, resulting in a fluorescently labeled PLA- $b$-PHPMA for potential drug delivery. ${ }^{44}$

In addition, nitroxide-medicated radical polymerization ${ }^{45}$ and conventional free radical polymerization ${ }^{46,47}$ have been explored for the preparation of PLA-based ABPs.

\subsection{PEG}

Poly(ethylene glycol) (PEG) is the most commonly applied nonionic, hydrophilic polymer. PEG is FDA-approved for clinical use; it has prolonged blood circulation and diminished reticuloendothelial system (RES) uptake. ${ }^{48}$ Thus, PEGylation 
(a)

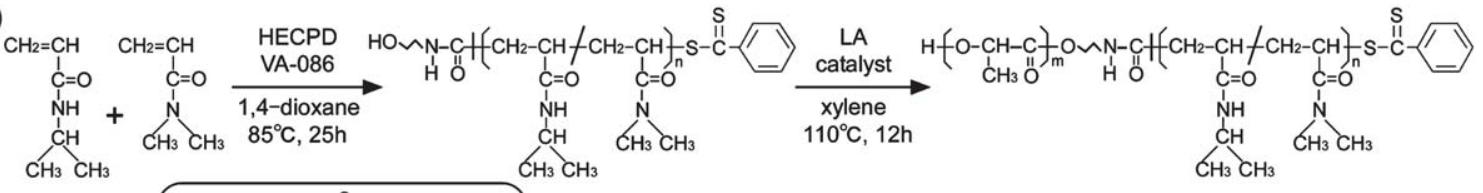

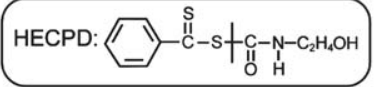

(b)
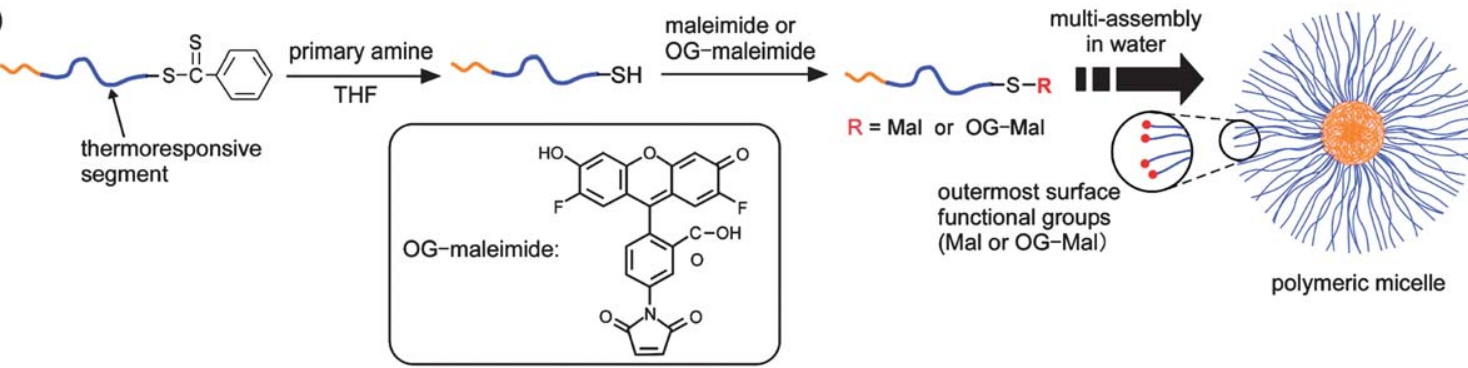

Fig. 4 Synthesis of PLA- $b$-P(NIPAM-co-DMAm) (a) and conversion of thermoresponsive polymer termini and formation of polymeric micelles (b). ${ }^{42}$ Copyright 2009 Wiley InterScience.

has been extensively employed as an effective method of choice in the development of biocompatible materials for many biological and biomedical applications. ${ }^{49}$ Recently, the pros and cons for PEGylation for drug delivery have been reviewed. ${ }^{50}$

PEG has been used to modify hydrophobic PLA, typically as initiating species for the ROP of LA to prepare PEG-containing PLA ABPs. Typical examples include self-assembled NPs of methoxy-capped PEG (mPEG)- $b$-PLA, ${ }^{51}$ mPEG- $b$-poly(hexylsubstituted LA), ${ }^{52}$ PLA- $b$-PEG- $b$-PLA, ${ }^{53}$ PEG/star- $b$-PLA, ${ }^{54}$ PLGA- $b$-PEG, ${ }^{55}$ and $\mathrm{H} 40$ hyperbranched polyester-modified PLA- $b$-PEG,${ }^{56}$ as well as vesicle of $\mathrm{mPEG}_{44}-b-\mathrm{PLA}_{x}$ (note that 44 and $x$ are the degree of polymerization). ${ }^{57}$ The modification of PLA with conventional PEG is relatively facile, compared to other methods. However, one of its drawbacks involves the lack of functional groups in the resulting PEG- $b$-PLA that can be used for further bioconjugation. Several approaches have been proposed to synthesize functional PEG- $b$-PLA. A triblock copolymer consisting of $\mathrm{mPEG}$, pendent propargyl-containing polymer as a middle block, and PLA was prepared and selfassembled to form micellar NPs. The propargyl groups were used for conjugation with azido-functionalized hemoglobin molecules through click-type $\mathrm{Cu}(\mathrm{I})$-mediated Huisgen 1,3-dipolar cycloaddition as artificial oxygen carriers. ${ }^{58}$ Fig. 5 illustrates the synthesis of $\mathrm{COOH}$-functionalized PEG- $b$-PLGA by coupling reaction of PLGA (-COOH group) with $\mathrm{NH}_{2}-\mathrm{PEG}-\mathrm{COOH}$ ( $-\mathrm{NH}_{2}$ group). The resultant ABPs were self-assembled in the presence of paclitaxel through nanoprecipitation to form paclitaxel-loaded NPs. The terminal $-\mathrm{COOH}$ groups at the end of PEG chains of self-assembled NPs were bioconjugated with aptamer (nucleic acids as cancer therapeutics) for targeted cancer chemotherapy. ${ }^{59}$

\subsection{Polypeptides}

Synthetic polypeptides based on $\alpha$-amino acids, poly $(\alpha$-amino acids), are biocompatible and biodegradable. As shown in

a

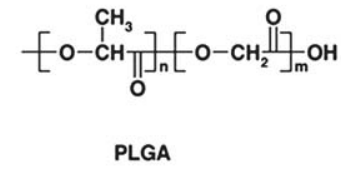

b

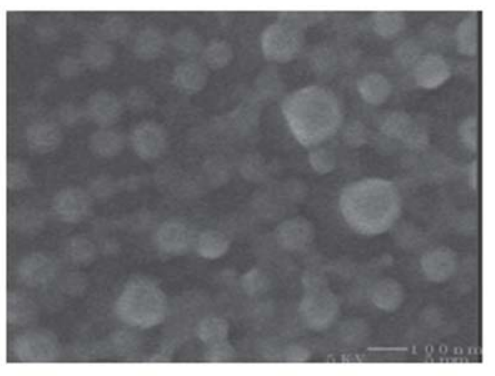

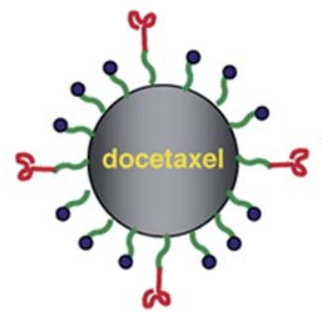
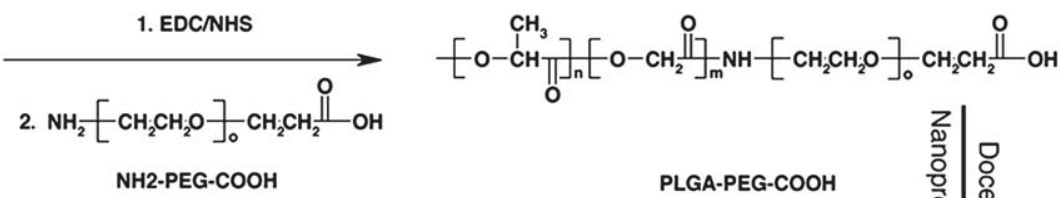

PLGA-PEG-COOH
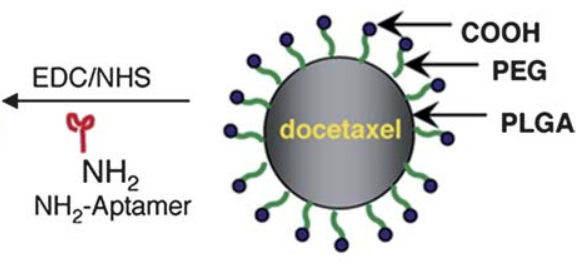

Fig. 5 A schematic illustration (a) and a SEM image (b) of paclitaxel-loaded NP-aptamer bioconjugates for cancer chemotherapy. ${ }^{59}$ Copyright 2006 PNAS. 
Fig. 6a, several poly( $\alpha$-amino acids) possess pendent functional groups, including carboxylic acid $(-\mathrm{COOH})$ for aspartic acid and glutamic acid, thiol $(-\mathrm{SH})$ for cysteine, and amine $\left(-\mathrm{NH}_{2}\right)$ for lysine. These functional groups are further utilized for bioconjugation and shell-crosslinking. These unique properties have promoted the use of functional poly( $\alpha$-amino acids) as hydrophilic polymers to coat hydrophobic PLA NPs. Two general methods have been proposed for the preparation of unique PLA-based poly $(\alpha$-amino acids) ABPs. Both methods require the protective group chemistry of $\alpha$-amino acids to avoid the side reactions of $-\mathrm{NH}_{2}$ and $-\mathrm{COOH}$ groups during polymerization.

A facile method involves the ROP of $\alpha$-amino acid $N$-carboxyanhydrides (NCAs) from $\mathrm{NH}_{2}$-terminated PLA $\left(\mathrm{NH}_{2}-\right.$ PLA). Fig. 6b shows the $\alpha$-amino acid NCAs reported in the literature. This method generally includes three steps; (1) synthesis of $\mathrm{NH}_{2}-\mathrm{PLA}$, (2) ROP of $\alpha$-amino acid NCA, and (3) removal of NCA groups through hydrolysis or catalytic hydrogenation. The preparation of PLA- $b$-poly(aspartic acid) (PLA- $b$ PAsp) is illustrated in Fig. 7. ${ }^{60}$ First, $\mathrm{BOC}-\mathrm{NH}_{2}-\mathrm{PLA}$ was synthesized by the ROP of LA in the presence of BOC-aminoethanol, which was synthesized by the reaction of aminoethanol

(a) Structure of functional amino acids

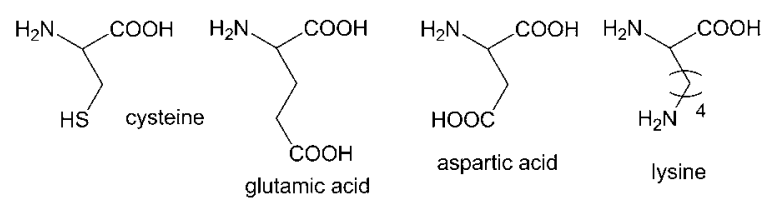

(b) Amino acid N-carboxyanhydrides

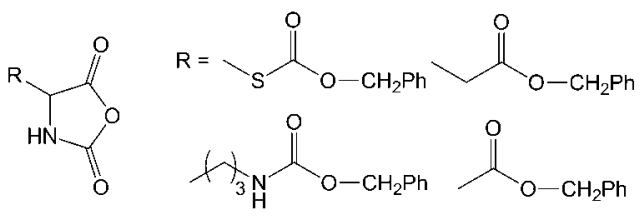

Fig. 6 Examples of $\alpha$-amino acids having pendent functional groups (a) and $\alpha$-amino acid $N$-carboxyanhydrides (b).

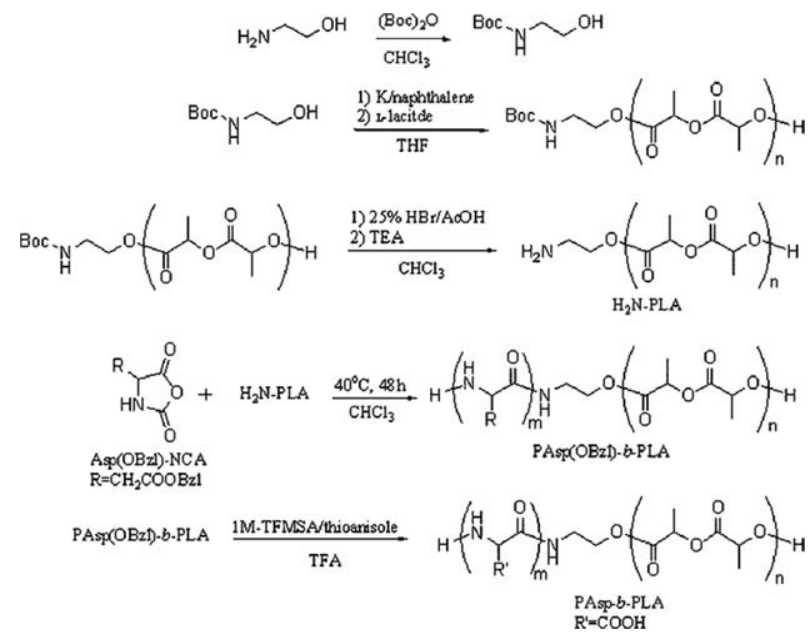

Fig. 7 An illustration of synthesis of PLA- $b$-PAsp block copolymer. ${ }^{60}$ Copyright 2004 Wiley InterScience. with $(\mathrm{BOC})_{2} \mathrm{O}$. The $\mathrm{BOC}$ group of $\mathrm{BOC}-\mathrm{NH}_{2}-\mathrm{PLA}$ was then removed by hydrolysis for the formation of $\mathrm{NH}_{2}-\mathrm{PLA} .{ }^{61} \mathrm{Next}$, the ROP of $\beta$-benzyl-L-aspartate NCA (BLA-NCA) in the presence of $\mathrm{NH}_{2}-\mathrm{PLA}$ as the macroinitiator yielded PLA- $b$-P(Asp NCA), a precursor of PLA- $b$-PAsp by hydrolysis. The resulting PLA- $b$-PAsp ABP formed core/shell type biodegradable micelles with a diameter of $<50 \mathrm{~nm}^{62}$

For the preparation of mPEG- $b$-PLA- $b$-poly(L-glutamic acid) (PGlu) triblock copolymer, $\mathrm{NH}_{2}$-terminated mPEG- $b$-PLA was prepared by ROP of LA in the presence of $\mathrm{MPEG}$, reaction with tert-butyloxycarbonyl-L-phenylalanine (Phe-BOC), and removal of BOC groups. The ROP of $\gamma$-benzyl-L-glutamate NCA (BLG-NCA) in the presence of $\mathrm{NH}_{2}$-terminated mPEG- $b$-PLA then yielded mPEG- $b$-PLA- $b-\mathrm{P}(\mathrm{BLG}-\mathrm{NCA})$, a precursor of mPEG- $b$-PLA- $b$-PGlu by catalytic hydrogenation. ${ }^{63}$ Similar approach has resulted in PLA- $b$-PGlu- $b$-PLA triblock copolymer. The pendent $\mathrm{COOH}$ groups of the triblock copolymer were further modified with RGD peptide for targeted drug delivery applications. ${ }^{64}$ The synthesis of mPEG- $b$-PLA- $b$ poly(L-lysine $)^{65}$ and PLA- $b$-poly(L-cysteine $)^{66}$ was also reported.

The coupling reaction has been explored. An example includes the synthesis of PLGA-b-PGlu by the carbodiimide coupling reaction of $\mathrm{NH}_{2}$-terminated PGlu with $\mathrm{COOH}$-terminated PLGA in the presence of 1-ethyl-(3-dimethylaminopropyl) carbodiimide (EDC) in water. The $\mathrm{COOH}$-terminated PLGA was prepared by the reaction of $\mathrm{OH}$-terminated PLGA with succinic anhydride. These ABPs exhibited $\mathrm{pH}$ responsiveness; their morphologies varied from disordered forms to micelles, and further to vesicles as $\mathrm{pH}$ increased from 4 to $9 .{ }^{67}$ PLA- $b$-PGlu was prepared by coupling reaction of OH-terminated PLA with $\mathrm{NH}_{2}$-terminated PGlu in the presence of $N, N^{\prime}$-carbonyldiimidazole (CDI). The resulting ABPs self-assembled to form micellar NPs. Their terminal $\mathrm{COOH}$ groups reacted with galactosamine, yielding galactosylated NPs. ${ }^{68}$ In addition, grafting of PLA onto poly(hydroxyethyl aspartamide) copolymers has been reported. ${ }^{69}$

\subsection{Polysaccharides}

Polysaccharides are naturally occurring biopolymers that are abundant in nature, intrinsically biodegradable and renewable. Ethyl cellulose ${ }^{70}$ cellulose, ${ }^{71}$ cellulose fiber, ${ }^{72}$ and hydroxypropyl cellulose $^{73}$ were grafted with PLA. PLA-grafted pullulan, ${ }^{74}$ amylose, ${ }^{75}$ and dextran ${ }^{76}$ were prepared through three steps: silylation of hydroxyl groups, ROP of LA initiated with remaining hydroxyl groups, and silylether deprotection. These PLA-grafted polysaccharides exhibit amphiphilic characteristics. Thus, they were useful as biodegradable films and fibers as well as enabled stabilizing both direct and inverse miniemulsions. ${ }^{77-79} \mathrm{In}$ addition, PLA-grafted dextran-based microspheres were prepared by solvent evaporation/extraction method in water-inoil-in-water $(\mathrm{W} / \mathrm{O} / \mathrm{W})$ emulsion. The release behavior of bovine serum albumin ${ }^{80}$ and lysozyme ${ }^{81}$ from microspheres was examined.

Similarly, hyaluronic acid (HA) was grafted with PLA and PEG, yielding amphiphilic PLA- $g$-HA- $g$-PEG. Their selfassembly toward micelle formation as well as morphology and cytotoxicity of drug-loaded micelles were examined for targeted release of anticancer therapeutics. ${ }^{82}$ Recently, the synthesis of CL-grafted polysaccharides has been reviewed. ${ }^{83}$ 


\subsection{Polyurethanes with hydrophilic segments}

Polyurethanes are well-known synthetic polymers prepared by polyaddition through building blocks of urethane linkages. They are mainly used for industrial materials because they are tough and resistant to solvents and hydrolytic degradation. Several papers have reported the development of biodegradable PLA-containing polyurethanes as useful biomaterials for tissue engineering ${ }^{84}$ and drug delivery. ${ }^{85}$ Multiblock poly(ether ester polyurethane) comprising PLA, PEG, and poly(propylene oxide) segments was synthesized. Their structures were characterized with composition using NMR and IR spectroscopy and molecular weight using GPC. These ABPs self-assembled to form micellar NPs having PEG coronas. A fluorescent technique with 1,6-diphenyl-1,3,5-hexatriene (DPH) was employed to determine the CMC of these ABPs. These polymers exhibited thermo-reversible sol-gel transition behavior at critical gelation concentrations ranging from 7 to $9 \mathrm{wt}^{\%} .{ }^{84}$ Pendent $\mathrm{COOH}$-containing polyurethane comprising PLA and PEG was synthesized to form micellar NPs through self-assembly. ${ }^{85}$

\section{Bio-related applications of PLA-based amphiphilic block copolymers}

\subsection{Biological evaluations - cytotoxicity}

PLA-based ABPs described in Section 2 are composed of PLA (and its copolymers) and hydrophilic polymer. These individual building block polymers are known to be non-toxic and biocompatible. A question is if the PLA-based copolymers are still non-toxic. PLA- $b$-PHPMA ABPs was tested for cytotoxicity using a MTT assay (a standard colorimetric assay for the evaluation of cell viability). The cell viability was evaluated to be close to $100 \%$ over $72 \mathrm{~h}$, indicating that PLA- $b$-HPMA is nontoxic to cells up to a concentration of $3 \mathrm{mg} \mathrm{mL} \mathrm{mL}^{-1}{ }^{44}$ A PLA-based thermoresponsive ABP was also evaluated to be non-cytotoxic. ${ }^{\mathbf{4 2}}$

\subsection{Self-assembled nanoparticles for drug delivery}

Polymeric micelles as drug delivery systems (DDS) offer many advantages. ${ }^{86,87}$ These advantages include (1) colloidal stability with low $\mathrm{CMC}$, (2) tunable sizes with narrow size distribution, (3) ability to preserve the activities of drugs during circulation in blood, (4) high physical loading efficiency of drugs, (5) bioconjugation for active targeting to specific diseased cells, and (6) controllable release of drugs upon external stimuli and degradation. ${ }^{88}$ A broad variety of self-assembled NPs of PLA-based ABPs has been explored as effective delivery carriers of encapsulated biomolecules. Examples include plasmidDNA $^{89}$ and carboxyfluorescein (a fluorescent dye as model drug), ${ }^{43}$ as well as hydrophobic anticancer drugs such as mainly paclitaxel, ${ }^{40,59,68,90}$ CPT-11, ${ }^{91}$ doxorubicin (Dox), ${ }^{92,93}$ and gliclazide (a second-generation hypoglycemic sulfonylurea agent) ${ }^{85}$

For DNA delivery, PLA- $b$-PDMAEMA was prepared and the PDMAEMA block was protonated. The self-assembled core/shell NPs consisted of a PLA core (loading drugs) surrounded with protonated PDMAEMA coronas. The cationic PDMAEMA coronas facilitated DNA loading through ionic interactions with anionic phosphate groups of DNA molecules. For drug delivery, hydrophobic drugs are loaded inside core/shell NPs of PLA-based ABPs. The drug loading level (amount of drugs loaded in NPs) and encapsulation efficiency (ratio of the amount of loaded drugs to feed drugs) are characterized using $\mathrm{UV} /$ vis spectroscopy for UV-active drugs and HPLC for paclitaxel. One of the important formulation parameters that significantly influence the drug loading level appears to be the feeding level of drugs. For example, paclitaxel-loaded thermo- and $\mathrm{pH}-$ dual-responsive NPs of PLA- $b$-P(NIPAM-co-acrylic acid) had a diameter of $135 \mathrm{~nm}$. The paclitaxel loading increased from 3 to $30 \%$ with an increasing amount of feeding paclitaxel from 5 to $50 \%$ based on copolymers. ${ }^{94}$ In vitro release kinetics of paclitaxel from PLA-based NPs has been explored. Several reports have shown that more than three days are required for cumulative release of $80 \%$ paclitaxel at $\mathrm{pH}=4.0$ (Fig. 8). ${ }^{90}$ Such a slow release may be attributed to delayed diffusion through the hydrophobic PLA core due to both hydrophobic interactions as well as the slow hydrolysis of the ester linkages of the PLA backbones. Introducing $\mathrm{pH}$-responsive block copolymers into PLA-based NPs enhances the cumulative release rate of paclitaxel; in this case, up to $80 \%$ of paclitaxel is released from the mixed micelles within $5 \mathrm{~h}$ upon degradation at $\mathrm{pH}=6.4 .^{93}$

Dox, an anticancer drug, was covalently conjugated to mPEG- $b$-P(LA-co-dihydroxymethylpropylene carbonate, DHP) via either carbamate or acid-labile hydrazone linkage. The $\mathrm{OH}$ groups of DHP units were activated with 4-nitrophenyl chloroformate and then reacted with amino groups of Dox.
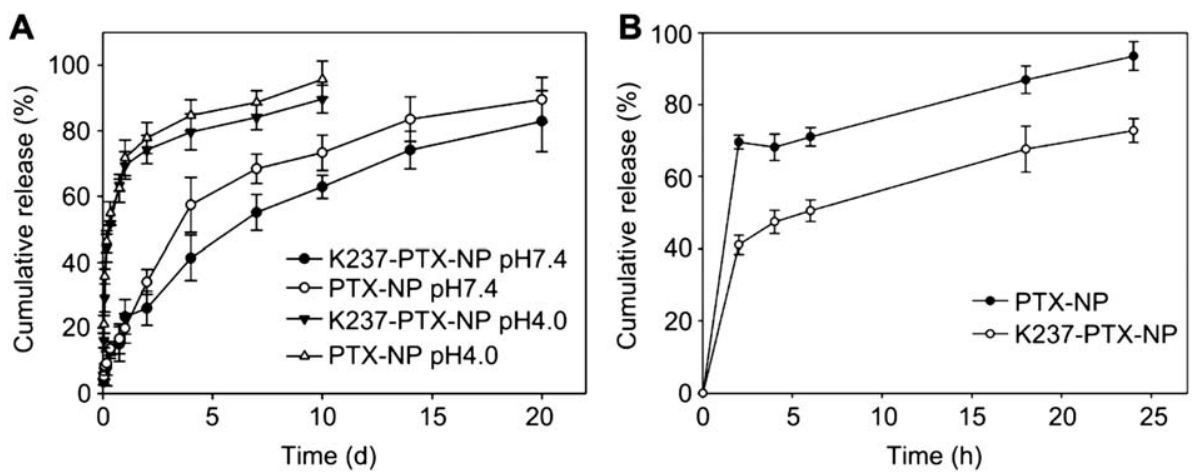

Fig. 8 In vitro release of paclitaxel from NPs of PLA- $b$-PEG in PBS ( $\mathrm{pH} 7.4$ and 4.0) (A) and in the mixture medium $(1: 1 \mathrm{v} / \mathrm{v})$ of PBS (pH $=7.4)$ and rat plasma (B).$^{90}$ Copyright 2010 Elsevier. 
The resultant mPEG- $b$-P(LA-DHP)/Dox co-assembled with folic acid (FA)-conjugated mPEG- $b$-P(LA-co-DHP)/FA. The resulting multifunctional mixed micelles exhibited $\mathrm{pH}$-dependent release behavior: the release of Dox upon cleavage of carbamate and hydrazone bonds was enhanced in acidic $\mathrm{pH} .{ }^{95}$

Cellular uptake has been studied using laser confocal fluorescence microscopy (LCFM). For the studies, NPs of PLA-based ABPs were encapsulated with fluorescence dyes and incubated with living cells such as HeLa and 3T3 cells. LCFM results suggest that these NPs are uniformly distributed inside cells. Active targeting is a promising approach toward increasing local accumulation of NPs in diseased tissue.96,97 This approach requires the design and preparation of functional NPs that are further conjugated with targeting biomolecules to specific cells through specific receptor-ligand or antigen-antibody interactions. These biomolecules that have been attached to PLA-based NPs include folate, ${ }^{56,98} \mathrm{RGD}^{64}$ peptide, ${ }^{90,93}$ carbohydrate (galactosamine), ${ }^{68}$ and aptamer. ${ }^{59}$

Tumor targeting ability of peptide (CRKRLDRN)-conjugated, pH-responsive mixed micellar NPs was examined using the noninvasive and live optical imaging system (Fig. 9). The NPs containing $1 \mathrm{mg} \mathrm{kg}^{-1}$ of TRIRC (a fluorescent dye) were administered intravenously into MDA-MB21 human breast tumor-bearing mice. Compared to the control non-conjugated with the targeting peptide, total photon counts (quantified for fluorescent signals) at targeted tumor tissues were larger for peptide-conjugated NPs. In addition, ex vivo fluorescence images of excised organs show tumor-targeting ability of peptideconjugated NPs. ${ }^{93}$

\subsection{Diagnostics/imaging platforms}

Colloidal inorganic nanocrystals have unique physical and optical properties attributed to nanoscale phenomena. These nanocrystals, typically including magnetic NPs (MNPs) and quantum dots (QDs), have proved to be useful as building block for the development of nanomaterials and biomaterials in nanoscience and biotechnology. MNPs have great potential for magnetic resonance imaging (MRI) that is a non-invasive imaging method utilized in clinical medicine. This MRI method is based on the relaxation of protons in tissues; upon accumulation in tissues, magnetic NPs enhance proton relaxation of

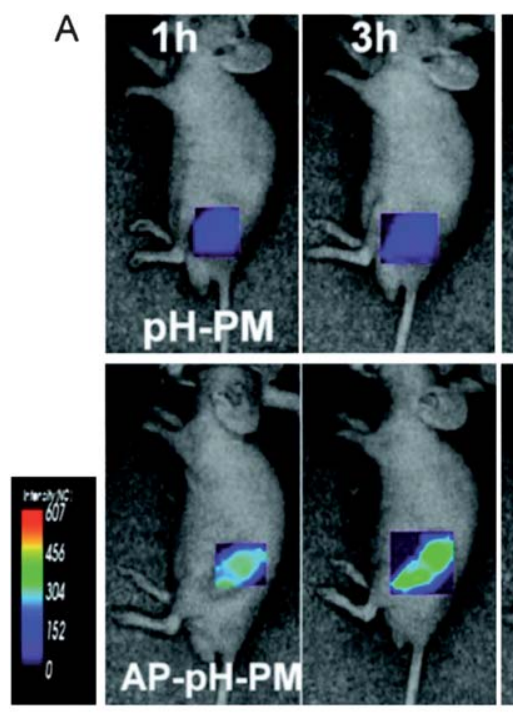

B

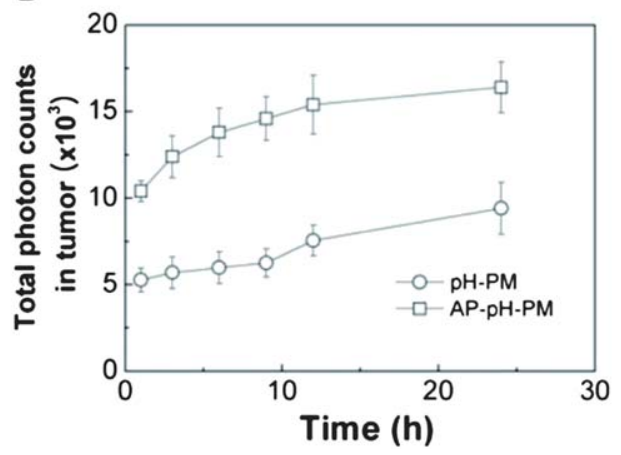

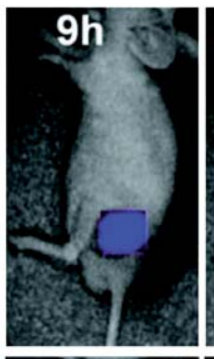
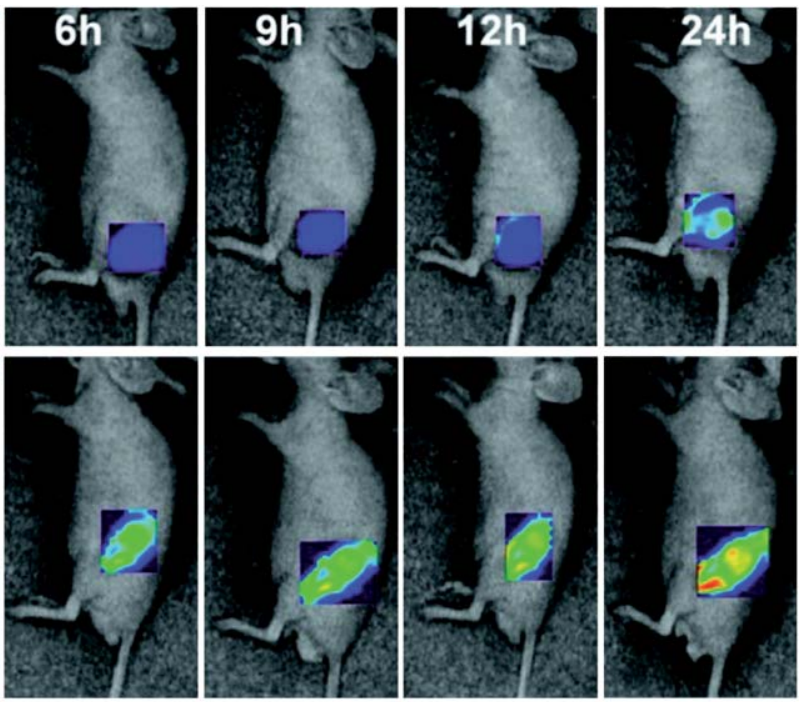

C
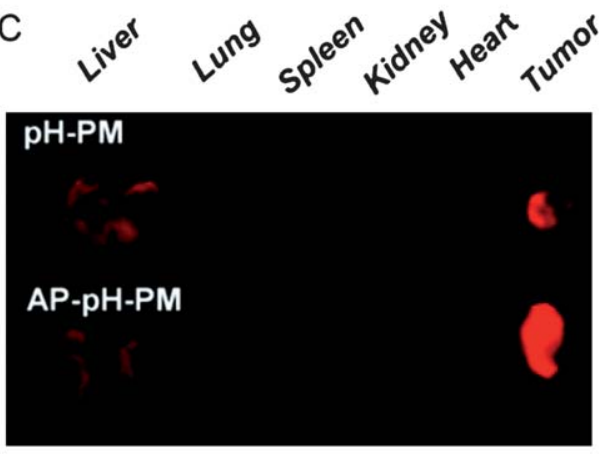

Fig. 9 In vivo and ex vivo biodistribution of peptide-conjugated, pH-responsive micelles containing TRIRC (a fluorescent dye), compared with a control without peptide conjugation; in vivo fluorescence image of MDA-MA-231 tumor-bearing mice injected with both NPs (a), quantification of in vivo tumor targeting ability of both NPs recorded as total photon counts per centimetre squared per steradian $\left(\mathrm{p} \mathrm{s}^{-1} \mathrm{~cm}^{-2} \mathrm{sr}^{-1}\right)$ per each tumor at $1 \mathrm{day}$ post-injection $(n=3)(\mathrm{b})$, and an ex vivo fluorescence image of dissected organs after 24 h post-injection of both NPs (c). ${ }^{93}$ Copyright in 2010 American Chemical Society. 
specific tissues when compared with the surrounding tissues, serving as a MR contrast agent. ${ }^{99-101} \mathrm{CdX}(\mathrm{X}=\mathrm{Se}, \mathrm{S}$, and Te $)$ QDs have unique photoluminescence properties such as narrow and size-dependent emission spectra, multicolor excitation, and excellent photostability against photobreaching. Due to these distinct advantages, they are useful as biological labeling in biological applications. ${ }^{102-105}$

Self-assembled NPs of PLA-based ABPs have been loaded with MNPs and QDs. This requires the modification of metal nanocrystal surfaces with hydrophobic ligands, facilitating their encapsulation in the hydrophobic PLA-based inner core. A typical example includes $\mathrm{COOH}$-terminated PLA- $b$-PEG that self-assembled in the presence of hydrophobic MNPs and Dox, resulting in Dox-loaded, MNP-embedded core/shell NPs. These NPs were then functionalized with therapeutic antibodies targeting to tumors for a MRI probe (Fig. 10). After internalization into cells, Dox was released upon the collapse of micellar aggregates and the viability of cancer cells was monitored using the MRI. ${ }^{106}$ Other examples include self-assembled NPs of wellcontrolled PLA- $b$-POEOMA functionalized with folate ${ }^{107}$ and a mixture of maleimide-terminated PEG- $b$-PLA and methoxyterminated PEG- $b$-PLA. ${ }^{108} \mathrm{CdSe} / \mathrm{ZnS}$ core/shell QDs were encapsulated in PEG- $b$-PLA NPs for biomedical imaging probes and drug delivery carriers. ${ }^{109}$

Several methods that enable the encapsulation of metal nanocrystals in PLA homopolymers have been explored, typically including heterogeneous polymerization in miniemulsion ${ }^{\mathbf{1 1 0}}$ and supercritical carbon dioxide, ${ }^{111}$ and precipitation-solvent evaporation. ${ }^{112,113}$ In addition, other methods to prepare a PLA layer on single crystals have been explored, including surface modification of nanocrystals with thiol-terminated PLA ${ }^{114}$ and surface-initiated ROP of LA. ${ }^{66}$

\subsection{Crosslinked hydrogels for tissue engineering}

Hydrogels are a three-dimensional network crosslinked with hydrophilic polymers. They have biocompatibility, high water content, tunable chemical and physical structure, and enhanced mechanical properties. Due to these unique properties, hydrogels have a great potential in the development of useful biomaterials for biological and biomedical applications. ${ }^{115-117}$ Effective hydrogels have been extensively explored for regenerative

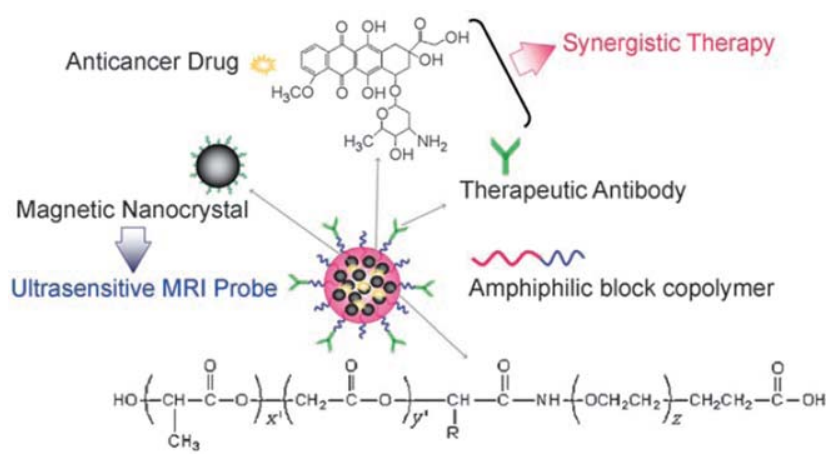

Fig. 10 Fabrication of a MRI probe from core/shell NPs of $\mathrm{COOH}-$ functionalized PLA- $b$-PEO consisting of PLA inner core embedded with MNPs and doxorubicin and a shell functionalized with targeting therapeutic antibodies to tumor. ${ }^{106}$ Copyright 2007 Wiley InterScience. medicine (or tissue engineering) and drug delivery, ${ }^{118-121}$ as well as for the development of a variety of advanced biomaterials including biosensors and detection, ${ }^{122-124}$ microfluidic biomaterials, ${ }^{125-127}$ drug conjugates, ${ }^{128}$ catalysis, ${ }^{129}$ and photonic crystals. ${ }^{130,131}$ Both synthetic and biopolymer-based hydrogels are generally prepared via two methods: chemical crosslinking and physical crosslinking. ${ }^{\mathbf{8 3 , 1 3 2}}$ PLA as well as PLA-based ABPs have been utilized for the development of well-defined biodegradable hydrogels by both chemical and physical crosslinking methods. Typical methods include temperature-induced sol-gel transition, stereocomplexation, ionic interaction, and photoinduced crosslinking polymerization.

Temperature-induced sol-gel transition of in situ thermogelling polymers is attractive for tissue engineering and drug delivery applications. This is because an aqueous solution of in situ gel-forming polymers is in a low viscous sol phase at room temperature or lower, while it becomes a semisolid or gel with an increasing temperature. ${ }^{133-135}$ ABPs comprising PEG and PLA (or PCL) enabled in situ formation of crosslinked hydrogels in water $(>20 \mathrm{wt} \%) .{ }^{136}$ 8-Arm PEG- $b$-PLLA conjugated with cholesterol self-assembled to form temperature-induced hydrogels as an injectable scaffold for tissue engineering. ${ }^{137} \mathrm{~A}$ multiblock copolymer of alternating PEG and PLA blocks was synthesized by polycondensation of PEG with $\alpha, \omega$-dicarboxylic acid terminated PLA, which was prepared by the reaction of diol terminated PLA with succinic anhydride. This multiblock copolymer self-assembled to form micelles with a diameter of $20 \mathrm{~nm}$ in water at low temperature; as temperature increased, these micelles were aggregated to a larger size. The key parameters that affect sol-gel transition temperature and gel window are molecular weight and composition of block copolymers. ${ }^{138}$ Similar approach was applied for the synthesis of thermosensitive PCL-based multiblock copolymers. ${ }^{139} \mathrm{~A} \mathrm{pH}$ - and thermosensitive triblock copolymer of P(CL- $c o-\mathrm{LA})-b$-PEG- $b$-P(CL- $c o$ LA) terminated with sulfamethazine end groups was synthesized by the ring opening copolymerization of CL and LA in the presence of PEG as a ROP initiator. This copolymer exhibited gelling behavior in response to $\mathrm{pH}$ and temperature. ${ }^{140}$

Stereocomplexation has been explored to synthesize various types of PLA-based, physically crosslinked hydrogels in water. A mixture of linear PLLA- $b$-PEG and PDLA- $b$-PEG formed physically crosslinked hydrogels through stereocomplexation of PLLA and PDLA blocks. Mechanical properties (storage and loss moduli) increased over the mixing time, indicating the formation of PLA-based stereocomplexed hydrogels. ${ }^{141}$ Similar approach was utilized for the synthesis of physical hydrogels from stereocomplex of (PLLA) $)_{8}-b$-PEG and (PDLA) $)_{8}-b$-PEG star block polymers. ${ }^{142}$ Dextran was modified with PLLA and PDLA and the mixture of dextran- $g$-PLLA and dextran- $g$ PDLA formed hydrogels ${ }^{143,144}$ and nanogels with a diameter of $70 \mathrm{~nm}^{145}$ in water. Control of the degree of polymerization and substitution of oligo-LA are key parameters that can affect the mechanical properties of hydrogels. Further, microspheres of dextran- $g$-HEMA prepared by chemical crosslinking were modified with either PLLA or PDLA, yielding PLLA- or PDLAtethered microspheres. Both microspheres formed macroscopic hydrogels through stereocomplexation (Fig. 11). ${ }^{146}$

Ionic interaction has been utilized to prepare biodegradable colloidal gels for moldable tissue engineering scaffolds. For the 


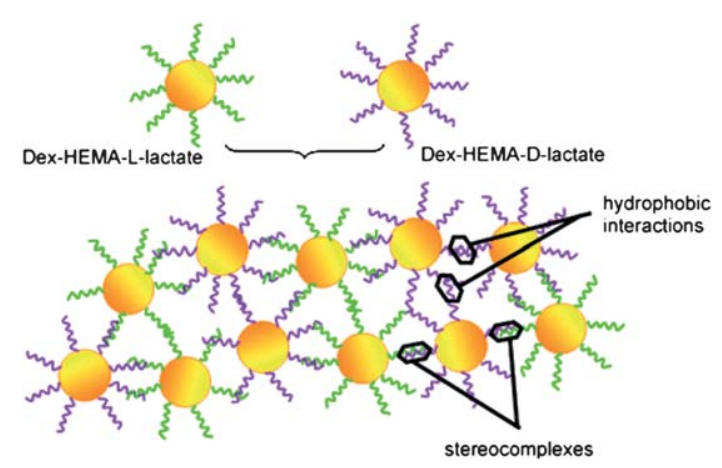

Fig. 11 Schematic representation of self-assembling hydrogels of PLLAand PDLA-tethered microspheres of dextran-g-HEMA. ${ }^{146}$ Copyright 2008American Chemical Society.

approach, oppositely charged colloidal NPs were first prepared by the solvent evaporation method of mixtures of PLGA with ionic polymers: polyvinylamine for cationic NPs and poly(ethylene-co-maleic acid) for anionic NPs. The oppositely charged NPs were then mixed to form colloidal network gels by ionic interaction. They exhibited pseudoplastic rheology behavior, which was utilized to construct differently shaped tissue scaffolds. The cytotoxicity study indicated that these colloidal gels were compatible with human umbilical cord matrix stem cells (HUCMSCs), suggesting the potential for effective tissue scaffolds (Fig. 12). ${ }^{147}$

Photo-induced crosslinking polymerization is a chemical crosslinking method that allows for the synthesis of covalently
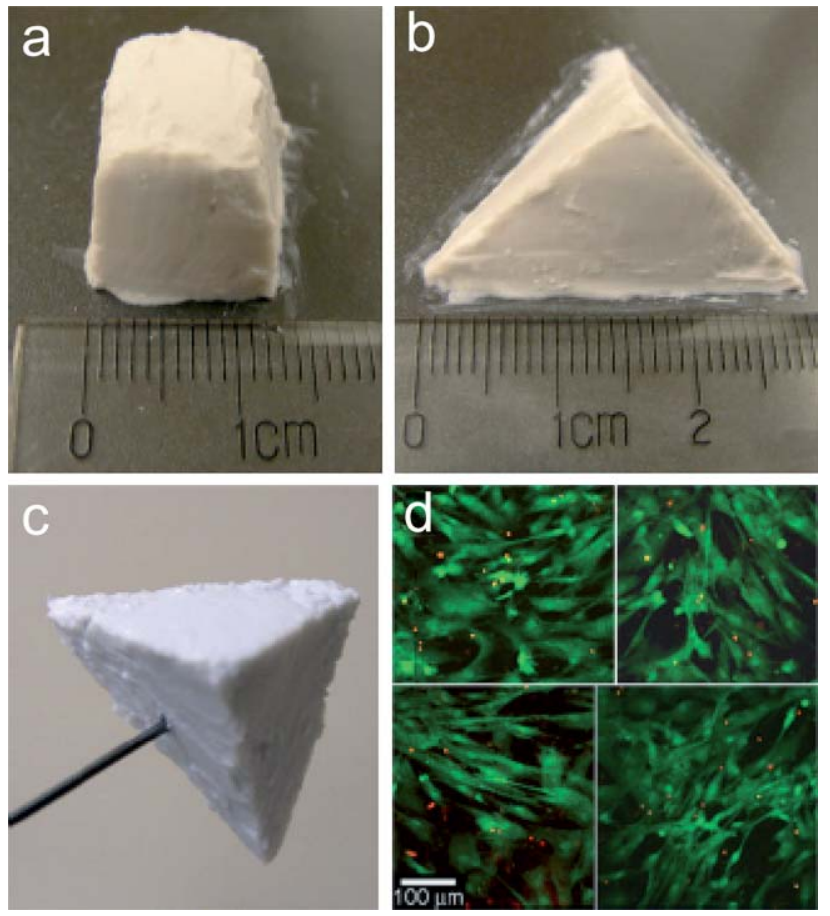

Fig. 12 Different shapes of scaffolds made from $20 \mathrm{wt} \%$ colloidal gels that are prepared by oppositely charged PLGA NPs (a and b), gels with sufficient cohesiveness to be handled by a 20 gauge needle (c), and human umbilical cord matrix stem cells cultured on colloidal gels (d). ${ }^{147}$ Copyright 2008 Wiley InterScience. crosslinked PLA-containing hydrogels. An approach involves the copolymerization of polymerizable-bearing species with LA. An example includes the synthesis of a copolymer consisting of PLA, PEG, and polyfumarate (containing backbone double bonds). ${ }^{148}$ The general approach involves the modification of PLA-based ABPs with photo-polymerizable groups, yielding corresponding dimethacrylates. One way is that the dimethacrylate derivatives of PLA-based ABPs are physically gelled in aqueous solution through either sol-gel transition or stereocomplexation. The resulting physical gels are then locked by permanent crosslinking through photopolymerization for dimensional stability and enhanced mechanical strength of hydrogels. ${ }^{149-151}$ In another way, the dimethacrylate derivatives are used as crosslinkers to copolymerize with other monomers. An example includes the synthesis of degradable, thermoresponsive PNIPAM-based hydrogels by free radical crosslinking polymerization of NIPAM, 2-methylene-1,3-dioxepane (MDO), and PCL- $b$-PEO- $b$-PCL dimethacrylate. These hydrogels degraded in alkali $\mathrm{pH}$ because of the degradability of PMDO. Because of the thermoresponsiveness of PNIPAM, they exhibited greater swelling at $4{ }^{\circ} \mathrm{C}$, below the low critical solution temperature (LCST), compared to $37{ }^{\circ} \mathrm{C}$, above LCST. An inverse opal of these hydrogels was fabricated PMMA microspheres as sacrificial templates. The size of pores in the inverse opal could be controlled by the size of PMMA spheres (Fig. 13). These results suggest that PNIPAM-based scaffolds are useful for tissue engineering applications. ${ }^{152}$ In order to improve cell interaction, biotinylated PLA-based hydrogels were synthesized by photo-crosslinking polymerization of a PLA-based dimethacrylate and a biotinylated PEG methacrylate. ${ }^{153}$

\subsection{Other PLA-based biomaterials for potential biomedical applications}

Glycopolymers are synthetic polymers with pendent carbohydrate moieties. Due to the importance of carbohydrates in biological recognition events such as specific carbohydrateprotein interactions and cell-cell interactions, significant efforts have been focused on the synthesis and application of wellcontrolled glycopolymers. ${ }^{154-156}$ An interesting example includes the synthesis of polygalactose containing nanocages (named hollow sugar balls) utilizing a combination of RAFT polymerization, shell-crosslinking, and degradation of PLA inner cores. First, 2-(benzylsulfanylthiocarbonylsulfanyl)ethanol, a functional RAFT agent, was synthesized ${ }^{157}$ and used both as an initiator for ROP of LA and then as a mediator for RAFT polymerization of 1,2:3,4-di- $O$-isopropylidene-6- $O$-acryloyl- $\alpha$-Dgalactopyranose (AIpGP), yielding PLA- $b$-PAIpGP. Next, isopropylene protecting groups on galactopyranose rings were removed and the resulting PLA- $b$-poly(6- $O$-acryloyl- $\alpha$-D-galactopyranose) (PLA- $b$-PAGP) ABPs self-assembled in water to form micellar NPs consisting of PLA core surrounded with PAGP corona. The PAGP shell was then crosslinked by free radical polymerization of 1,6-hexanedioldiacrylate. Finally, PLA inner core was dissolved by aminolysis with hexylamine. The resultant hollow nanocages, confirmed by transmission electron microscopy (TEM), could be useful for the delivery of drugs to liver. ${ }^{158}$ Semiconducting biomaterials were composed of salt leached PLGA and chloride-doped polypyrrole (PPy-Cl) 
a)
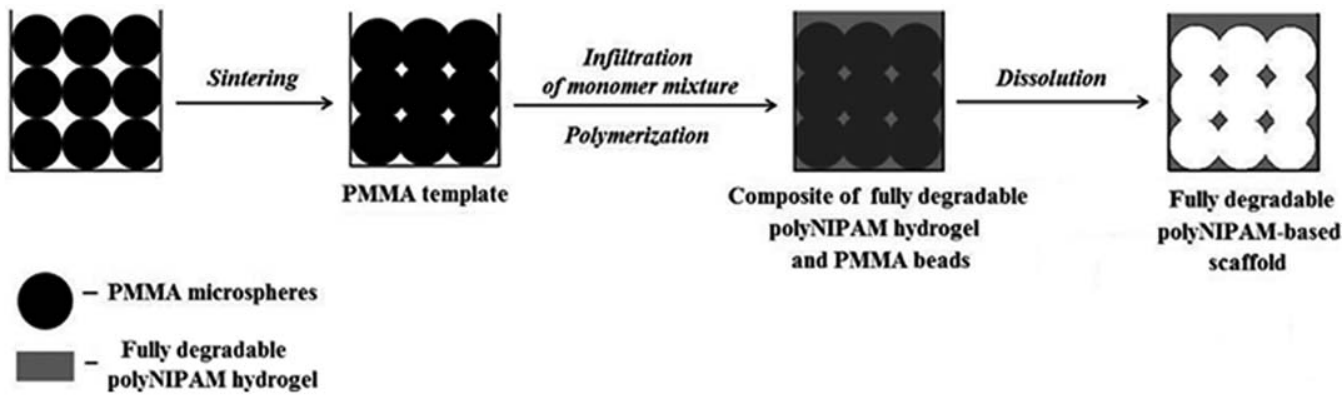

scaffold

b)

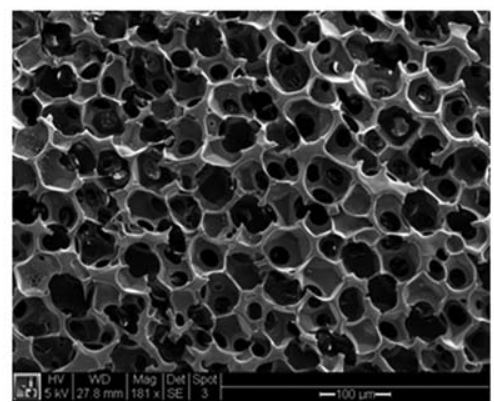

Fig. 13 Schematic illustration for fabrication (a) and SEM image (b) of inverse opal of degradable, thermoresponsive PNIPAM-based hydrogels. ${ }^{152}$ Copyright 2010 American Chemical Society.

conducting polymers. These hybrid materials were prepared via three-steps, including (1) spin-casting of PLGA salt, (2) salt leaching combined with PPy infusion, and (3) electrochemical synthesis of PPy-Cl. These PPy-PLGA blends may be useful for biomedical applications where good conductance and low impedance are desired. ${ }^{159}$

\section{Summary and outlook}

The hydrophobicity of PLA and its copolymers enhances the uptake of drug-loaded NPs, resulting in their short residence time in circulation, thus leading to a decrease in drug efficiency in vivo. One promising approach to address the problem is to design and synthesize ABPs that enable self-assembly toward the formation of core/shell NPs consisting of a hydrophobic core surrounded by hydrophilic coronas. A variety of strategies for the synthesis of novel ABPs based on PLA and its copolymers have been developed. Typical examples of hydrophilic polymers include well-controlled (meth)acrylates, PEG, polypeptides, polysaccharides, and polyurethanes. These PLA-based ABPs have found a variety of bio-related applications; typical examples include: self-assembled NPs for drug delivery, hydrogels for tissue engineering, and polymer-metal NP hybrids for imaging platforms. For drug delivery, various core/shell NPs have been developed to load hydrophobic anticancer drugs and genes through self-assembly and solvent evaporation. These ABPs have been designed to have functional groups that can be utilized for further bioconjugation to target specific cells, most often tumors. For tissue engineering, both physical and chemical crosslinking methods including temperature-induced sol-gel transition, stereocomplexation, ionic interaction, and photoinduced crosslinking polymerization have been utilized to prepare three-dimensional crosslinked hydrogels. For imaging platforms, metal NPs such as MNPs for MRI and QDs for fluorescent imaging have been encapsulated in core/shell NPs.
The future development of PLA-based ABPs for smart drug delivery requires that remaining challenges to be addressed. A challenge involves the improvement of slow and uncontrolled release kinetics of encapsulates for currently developed PLA-based ABPs. Another challenge is the development of multifunctional PLA-based nanostructured materials such as multi-responsive NPs, nanogels, and nanocapsules.

\section{Acknowledgements}

JKO greatly acknowledges financial supports from Natural Sciences and Engineering Research Council (NSERC) of Canada (Discovery Grant) and Concordia University (Start-up Funds).

\section{References}

1 K. E. Uhrich, S. M. Cannizzaro, R. S. Langer and K. M. Shakesheff, Chem. Rev., 1999, 99, 3181.

2 R. E. Drumright, P. R. Gruber and D. E. Henton, Adv. Mater., 2000, 12, 1841.

3 O. Dechy-Cabaret, B. Martin-Vaca and D. Bourissou, Chem. Rev., 2004, 104, 6147

4 G. B. Jacobson, R. Shinde, C. H. Contag and R. N. Zare, Angew. Chem., Int. Ed., 2008, 47, 7880.

5 J. E. Oh, Y. S. Nam, K. H. Lee and T. G. Park, J. Controlled Release, 1999, 57, 269.

6 C. Fonseca, S. Simoes and R. Gaspar, J. Controlled Release, 2002, 83, 273.

7 R. C. Mundargi, V. R. Babu, V. Rangaswamy, P. Patel and T. M. Aminabhavi, J. Controlled Release, 2008, 125, 193.

8 D.-H. Kim and C. Martin David, Biomaterials, 2006, 27, 3031.

9 J.-W. Yoo, N. Doshi and S. Mitragotri, Macromol. Rapid Commun., 2010, 31, 142.

10 R. M. Stayshich and T. Y. Meyer, J. Am. Chem. Soc., 2010, 132, 10920.

11 D. J. Darensbourg and O. Karroonnirun, Macromolecules, 2010, 43, 8880.

12 X. Hu, X. Chen, Z. Xie, H. Cheng and X. Jing, J. Polym. Sci., Part A: Polym. Chem., 2008, 46, 7022.

13 X. Jiang, E. B. Vogel, M. R. Smith, III and G. L. Baker, Macromolecules, 2008, 41, 1937. 
14 Z. Hu, X. Fan, H. Wang and J. Wang, Polymer, 2009, 50, 4175.

15 Z. Hu, X. Fan and G. Zhang, Carbohydr. Polym., 2010, 79, 119.

16 R. J. Pounder and A. P. Dove, Polym. Chem., 2010, 1, 260.

17 G. Gaucher, R. H. Marchessault and J.-C. Leroux, J. Controlled Release, 2010, 143, 2.

18 Y. Ikada, K. Jamshidi, H. Tsuji and S. H. Hyon, Macromolecules, 1987, 20, 904.

19 N. Nishiyama and K. Kataoka, Adv. Polym. Sci., 2006, 193, 67.

20 K. A. Davis and K. Matyjaszewski, Adv. Polym. Sci., 2002, 159, 1.

$21 \mathrm{~K}$. Matyjaszewski and T. P. Davis, Handbook of radical polymerization, John Wiley \& Sons Inc., Hoboken, 2002.

22 K. Matyjaszewski and J. Xia, Chem. Rev., 2001, 101, 2921.

23 J.-S. Wang and K. Matyjaszewski, J. Am. Chem. Soc., 1995, 117, 5614.

24 J. Chiefari, Y. K. Chong, F. Ercole, J. Krstina, J. Jeffery, T. P. T. Le, R. T. A. Mayadunne, G. F. Meijs, C. L. Moad, G. Moad, E. Rizzardo and S. H. Thang, Macromolecules, 1998, 31, 5559.

25 S. Perrier and P. Takolpuckdee, J. Polym. Sci., Part A: Polym. Chem., 2005, 43, 5347.

26 W. Nam Kwang, J. Watanabe and K. Ishihara, Biomacromolecules, $2002,3,100$.

27 J. Watanabe, T. Eriguchi and K. Ishihara, Biomacromolecules, 2002, 3, 1375 .

28 G.-H. Hsiue, C.-L. Lo, C.-H. Cheng, C.-P. Lin, C.-K. Huang and H.-H. Chen, J. Polym. Sci., Part A: Polym. Chem., 2007, 45, 688.

29 N. Karanikolopoulos, M. Zamurovic, M. Pitsikalis and N. Hadjichristidis, Biomacromolecules, 2010, 11, 430.

30 M. Spasova, L. Mespouille, O. Coulembier, D. Paneva, N. Manolova, I. Rashkov and P. Dubois, Biomacromolecules, 2009, 10, 1217.

31 W. Zhang, J. He, Z. Liu, P. Ni and X. Zhu, J. Polym. Sci., Part A: Polym. Chem., 2010, 48, 1079.

32 P. A. Wilbon, Y. Zheng, K. Yao and C. Tang, Macromolecules, 2010, 43, 8747.

33 F. F. Wolf, N. Friedemann and H. Frey, Macromolecules, 2009, 42, 5622.

34 E. Jubeli, L. Moine and G. Barratt, J. Polym. Sci., Part A: Polym. Chem., 2010, 48, 3178.

35 X. Jiang, S. Luo, S. P. Armes, W. Shi and S. Liu, Macromolecules, 2006, 39, 5987.

36 S. Fujii, Y. Cai, V. M. Weaver Jonathan and P. Armes Steven, J. Am. Chem. Soc., 2005, 127, 7304.

37 S. Fujii, Y. Cai, J. V. M. Weaver and S. P. Armes, J. Am. Chem. Soc., 2005, 127, 7304.

38 C. Giacomelli and R. Borsali, Macromol. Rapid Commun., 2008, 29, 573.

39 F. K. Wolf, A. M. Hofmann and H. Frey, Macromolecules, 2010, 43, 3314.

40 Z. Cao, Q. Yu, H. Xue, G. Cheng and S. Jiang, Angew. Chem., Int. $E d ., 2010,49,3771$.

41 J. Akimoto, M. Nakayama, K. Sakai and T. Okano, J. Polym. Sci., Part A: Polym. Chem., 2008, 46, 7127.

42 J. Akimoto, M. Nakayama, K. Sakai and T. Okano, Biomacromolecules, 2009, 10, 1331.

43 A. O. Saeed, S. Dey, S. M. Howdle, K. J. Thurecht and C. Alexander, J. Mater. Chem., 2009, 19, 4529.

44 M. Barz, F. K. Wolf, F. Canal, K. Koynov, M. J. Vicent, H. Frey and R. Zentel, Macromol. Rapid Commun., 2010, 31, 1492.

45 S. H. Kim, J. P. K. Tan, F. Nederberg, K. Fukushima, Y. Y. Yang, R. M. Waymouth and J. L. Hedrick, Macromolecules, 2009, 42, 25.

46 F. Kohori, K. Sakai, T. Aoyagi, M. Yokoyama, Y. Sakurai and T. Okano, J. Controlled Release, 1998, 55, 87.

47 C. J. F. Rijcken, T. F. J. Veldhuis, A. Ramzi, J. D. Meeldijk, C. F. van Nostrum and W. E. Hennink, Biomacromolecules, 2005, 6, 2343.

48 R. Gref, G. Miralles and E. Dellacherie, Polym. Int., 1999, 48, 251.

49 T. Bruckdorfer, Eur. Biopharm. Rev., 2008, 96.

50 K. Knop, R. Hoogenboom, D. Fischer and U. S. Schubert, Angew. Chem., Int. Ed., 2010, 49, 6288.

51 S. C. Kim, D. W. Kim, Y. H. Shim, J. S. Bang, H. S. Oh, S. W. Kim and M. H. Seo, J. Controlled Release, 2001, 72, 191.

52 T. Trimaille, K. Mondon, R. Gurny and M. Moeller, Int. J. Pharm., 2006, 319, 147.

53 Y. Dong and S.-S. Feng, J. Biomed. Mater. Res., Part A, 2006, 78, 12.
54 M. Stepanek, M. Uchman and K. Prochazka, Polymer, 2009, 50, 3638.

55 J. Cheng, A. Teply Benjamin, I. Sherifi, J. Sung, G. Luther, X. Gu Frank, E. Levy-Nissenbaum, F. Radovic-Moreno Aleksandar, R. Langer and C. Farokhzad Omid, Biomaterials, 2007, 28, 869.

56 M. Prabaharan, J. J. Grailer, S. Pilla, D. A. Steeber and S. Gong, Biomaterials, 2009, 30, 3009.

57 B. Du, A. Mei, K. Yin, Q. Zhang, J. Xu and Z. Fan, Macromolecules, 2009, 42, 8477.

58 Q. Shi, Y. Huang, X. Chen, M. Wu, J. Sun and X. Jing, Biomaterials, 2009, 30, 5077.

59 O. C. Farokhzad, J. Cheng, B. A. Teply, I. Sherifi, S. Jon, P. W. Kantoff, J. P. Richie and R. Langer, Proc. Natl. Acad. Sci. U. S. A., 2006, 103, 6315 .

60 H. Arimura, Y. Ohya and T. Ouchi, Macromol. Rapid Commun., 2004, 25, 743.

61 T. Ouchi, T. Uchida, H. Arimura and Y. Ohya, Biomacromolecules, 2003, 4, 477.

62 H. Arimura, Y. Ohya and T. Ouchi, Biomacromolecules, 2005, 6, 720 .

63 C. Deng, G. Rong, H. Tian, Z. Tang, X. Chen and X. Jing, Polymer, $2005,46,653$.

64 C. Deng, X. Chen, J. Sun, T. Lu, W. Wang and X. Jing, J. Polym. Sci., Part A: Polym. Chem., 2007, 45, 3218.

65 C. Deng, X. Chen, H. Yu, J. Sun, T. Lu and X. Jing, Polymer, 2007, 48, 139.

66 J. Sun, X. Chen, T. Lu, S. Liu, H. Tian, Z. Guo and X. Jing, Langmuir, 2008, 24, 10099.

67 Y. Yang, J. Cai, X. Zhuang, Z. Guo, X. Jing and X. Chen, Polymer, $2010, \mathbf{5 1}, 2676$.

68 H.-F. Liang, S.-C. Chen, M.-C. Chen, P.-W. Lee, C.-T. Chen and H.-W. Sung, Bioconjugate Chem., 2006, 17, 291.

69 E. F. Craparo, M. C. Ognibene, M. P. Casaletto, G. Pitarresi, G. Teresi and G. Giammona, Nanotechnology, 2008, 19, 485603.

70 W. Yuan, J. Yuan, F. Zhang and X. Xie, Biomacromolecules, 2007, 8, 1101 .

71 A. Mayumi, T. Kitaoka and H. Wariishi, J. Appl. Polym. Sci., 2006, 102, 4358.

72 H. Loennberg, Q. Zhou, H. Brumer, III, T. Teeri, E. Malmstroem and A. Hult, Biomacromolecules, 2006, 7, 2178.

73 E. Ostmark, D. Nystrom and E. Malmstrom, Macromolecules, 2008, 41, 4405 .

74 Y. Ohya, S. Maruhashi and T. Ouchi, Macromolecules, 1998, 31, 4662.

75 Y. Ohya, S. Maruhashi and T. Ouchi, Macromol. Chem. Phys., 1998, 199, 2017.

76 T. Ouchi, T. Kontani and Y. Ohya, Polymer, 2003, 44, 3927.

77 J. Raynaud, B. Choquenet, E. Marie, E. Dellacherie, C. Nouvel, J. L. Six and A. Durand, Biomacromolecules, 2008, 9, 1014.

78 C. Nouvel, J. Raynaud, E. Marie, E. Dellacherie, J. L. Six and A. Durand, J. Colloid Interface Sci., 2009, 330, 337.

79 E. Rotureau, J. Raynaud, B. Choquenet, E. Marie, C. Nouvel, J. L. Six, E. Dellacherie and A. Durand, Colloids Surf., A, 2008, 331, 84 .

80 T. Ouchi, T. Saito, T. Kontani and Y. Ohya, Macromol. Biosci., $2004,4,458$

81 K. Nagahama, T. Ouchi and Y. Ohya, Macromol. Biosci., 2008, 8, 1044.

82 G. Pitarresi, F. S. Palumbo, A. Albanese, C. Fiorica, P. Picone and G. Giammona, J. Drug Targeting, 2010, 18, 264.

83 J. K. Oh, D. I. Lee and J. M. Park, Prog. Polym. Sci., 2009, 34, 1261.

84 X. J. Loh, Y. X. Tan, Z. Li, L. S. Teo, S. H. Goh and J. Li, Biomaterials, 2008, 29, 2164.

85 J. Zhang, M. Wu, J. Yang, Q. Wu and Z. Jin, Colloids Surf., A, 2009, 337,200 .

86 A. Harada and K. Kataoka, Prog. Polym. Sci., 2006, 31, 949.

87 A. S. Mikhail and C. Allen, J. Controlled Release, 2009, 138, 214.

88 X. Huang, F. Du, R. Ju and Z. Li, Macromol. Rapid Commun., 2007, 28, 597.

89 X. Yue, Y. Qiao, N. Qiao, S. Guo, J. Xing, L. Deng, J. Xu and A. Dong, Biomacromolecules, 2010, 11, 2306.

90 D.-H. Yu, Q. Lu, J. Xie, C. Fang and H.-Z. Chen, Biomaterials, 2010, 31, 2278.

91 W.-C. Lee, Y.-C. Li and I. M. Chu, Macromol. Biosci., 2006, 6, 846. 
92 P.-Y. Li, P.-S. Lai, W.-C. Hung and W.-J. Syu, Biomacromolecules, 2010, 11, 2576.

93 X. L. Wu, J. H. Kim, H. Koo, S. M. Bae, H. Shin, M. S. Kim, B.H. Lee, R.-W. Park, I.-S. Kim, K. Choi, I. C. Kwon, K. Kim and D. S. Lee, Bioconjugate Chem., 2010, 21, 208.

94 L. Zhang, R. Guo, M. Yang, X. Jiang and B. Liu, Adv. Mater., 2007, 19, 2988.

95 X. Hu, S. Liu, Y. Huang, X. Chen and X. Jing, Biomacromolecules, 2010, 11, 2094.

96 J. D. Byrne, T. Betancourt and L. Brannon-Peppas, Adv. Drug Delivery Rev., 2008, 60, 1615.

97 O. Veiseh, J. W. Gunn and M. Zhang, Adv. Drug Delivery Rev., 2010, 62, 284.

98 S. H. Kim, J. H. Jeong, K. W. Chun and T. G. Park, Langmuir, 2005, 21, 8852 .

99 C. Sun, J. S. H. Lee and M. Zhang, Adv. Drug Delivery Rev., 2008, 60, 1252.

100 S. Mornet, S. Vasseur, F. Grasset and E. Duguet, J. Mater. Chem., 2004, 14, 2161.

101 J. K. Oh and J. M. Park, Prog. Polym. Sci., 2011, 36, 168-189.

102 A. P. Alvisatos, Nat. Biotechnol., 2004, $22,47$.

103 A. M. Smith, H. Duan, A. M. Mohs and S. Nie, Adv. Drug Delivery Rev., 2008, 60, 1226.

104 N. Tomczak, D. Janczewski, M. Han and G. J. Vancso, Prog. Polym Sci., 2009, 34, 393.

105 J. K. Oh, J. Mater. Chem., 2010, 20, 8433.

106 J. Yang, C.-H. Lee, H.-J. Ko, J.-S. Suh, H.-G. Yoon, K. Lee, Y.M. Huh and S. Haam, Angew. Chem., Int. Ed., 2007, 46, 8836.

107 F. Hu, K. G. Neoh and E.-T. Kang, Macromol. Rapid Commun., 2009, 30, 609 .

108 N. Nasongkla, E. Bey, J. Ren, H. Ai, C. Khemtong, J. S. Guthi, S.F. Chin, A. D. Sherry, D. A. Boothman and J. Gao, Nano Lett., 2006, 6, 2427.

109 J. Lee, J. H. Im, K. M. Huh, Y.-k. Lee and H. Shin, J. Nanosci. Nanotechnol., 2010, 10, 487.

110 M. Urban, A. Musyanovych and K. Landfester, Macromol. Chem. Phys., 2009, 210, 961.

111 A.-Z. Chen, Y.-Q. Kang, X.-M. Pu, G.-F. Yin, Y. Li and J.-Y. Hu, J. Colloid Interface Sci., 2009, 330, 317.

112 P.-W. Lee, S.-H. Hsu, J.-S. Tsai, F.-R. Chen, P.-J. Huang, C.-J. Ke, Z.-X. Liao, C.-W. Hsiao, H.-J. Lin and H.-W. Sung, Biomaterials, 2010, 31, 2425.

113 N. Butoescu, O. Jordan, P. Burdet, P. Stadelmann, A. Petri-Fink, H. Hofmann and E. Doelker, Eur. J. Pharm. Biopharm., 2009, 72, 529.

114 X. Hou, Q. Li, L. Jia, Y. Li, Y. Zhu and A. Cao, Macromol. Biosci., 2009, 9, 551.

115 A. S. Hoffman, J. Controlled Release, 1987, 6, 297.

116 R. Langer, Science, 2001, 293, 58.

117 R. Langer and N. A. Peppas, AIChE J., 2003, 49, 2990.

118 B. V. Slaughter, S. S. Khurshid, O. Z. Fisher, A. Khademhosseini and N. A. Peppas, Adv. Mater., 2009, 21, 3307.

119 N. A. Peppas, J. Z. Hilt, A. Khademhosseini and R. Langer, $A d v$. Mater., 2006, 18, 1345.

120 S.-W. Choi, J. Xie and Y. Xia, Adv. Mater., 2009, 21, 2997.

$121 \mathrm{~J} . \quad$ T. F. Keurentjes, M. F. Kemmere, H. Bruinewoud, M. A. M. E. Vertommen, S. A. Rovers, R. Hoogenboom, L. F. S. Stemkens, F. L. A. M. A. Peters, N. J. C. Tielen, D. T. A. van Asseldonk, A. F. Gabriel, E. A. Joosten and M. A. E. Marcus, Angew. Chem., Int. Ed., 2009, 48, 9867.

122 H. Tanaka, T. Isojima, M. Hanasaki, Y. Ifuku, H. Takeuchi, H. Kawaguchi and T. Shiroya, Macromol. Rapid Commun., 2008, 29, 1287.

123 C. Gota, K. Okabe, T. Funatsu, Y. Harada and S. Uchiyama, J. Am. Chem. Soc., 2009, 131, 2766.

124 Z. Zhu, C. Wu, H. Liu, Y. Zou, X. Zhang, H. Kang, C. J. Yang and W. Tan, Angew. Chem., Int. Ed., 2010, 49, 1052.

125 M. Cabodi, N. W. Choi, J. P. Gleghorn, C. S. D. Lee, L. J. Bonassar and A. D. Stroock, J. Am. Chem. Soc., 2005, 127, 13788.
126 N. W. Choi, M. Cabodi, B. Held, J. P. Gleghorn, L. J. Bonassar and A. D. Stroock, Nat. Mater., 2007, 6, 908.

127 A. P. Golden and J. Tien, Lab Chip, 2007, 7, 720.

128 O. P. Varghese, W. Sun, J. Hilborn and D. A. Ossipov, J. Am. Chem. Soc., 2009, 131, 8781

129 N. Yan, J. Zhang, Y. Yuan, G.-T. Chen, P. J. Dyson, Z.-C. Li and Y. Kou, Chem. Commun., 2010, 46, 1631.

130 J.-H. Kang, J. H. Moon, S.-K. Lee, S.-G. Park, S. G. Jang, S. Yang and S.-M. Yang, Adv. Mater., 2008, 20, 3061.

131 E. Tian, Y. Ma, L. Cui, J. Wang, Y. Song and L. Jiang, Macromol. Rapid Commun., 2009, 30, 1719.

132 N. Bhattarai, J. Gunn and M. Zhang, Adv. Drug Delivery Rev., 2010, 62, 83 .

133 Z. Yang, S. Pickard, N.-J. Deng, R. J. Barlow, D. Attwood and C. Booth, Macromolecules, 1994, 27, 2371.

134 S. Y. Lee, Y. Lee, S. Y. Chae, T. G. Park and C.-H. Ahn, Macromol. Chem. Phys., 2010, 211, 692.

135 S. Y. Park, Y. Lee, K. H. Bae, C.-H. Ahn and T. G. Park, Macromol. Rapid Commun., 2007, 28, 1172.

136 S. K. Agrawal, N. Sanabria-DeLong, G. N. Tew and S. R. Bhatia, Macromolecules, 2008, 41, 1774.

137 K. Nagahama, T. Ouchi and Y. Ohya, Adv. Funct. Mater., 2008, 18, 1220.

138 J. Lee, Y. H. Bae, Y. S. Sohn and B. Jeong, Biomacromolecules, 2006, 7, 1729.

139 S. J. Bae, M. K. Joo, Y. Jeong, S. W. Kim, W.-K. Lee, Y. S. Sohn and B. Jeong, Macromolecules, 2006, 39, 4873.

140 W. S. Shim, S. W. Kim and D. S. Lee, Biomacromolecules, 2006, 7, 1935.

141 S. Li, A. El Ghzaoui and E. Dewinck, Macromol. Symp., 2005, 222, 23 .

142 C. Hiemstra, Z. Zhong, L. Li, J. Dijkstra Pieter and J. Feijen, Biomacromolecules, 2006, 7, 2790.

143 S. J. de Jong, S. C. De Smedt, J. Demeester, C. F. van Nostrum, J. J. Kettenes-van den Bosch and W. E. Hennink, J. Controlled Release, 2001, 72, 47.

144 S. J. de Jong, S. C. De Smedt, M. W. C. Wahls, J. Demeester, J. J. Kettenes-van den Bosch and W. E. Hennink, Macromolecules, $2000,33,3680$

145 K. Nagahama, Y. Mori, Y. Ohya and T. Ouchi, Biomacromolecules, 2007, 8, 2135.

146 S. R. Van Tomme, A. Mens, C. F. van Nostrum and W. E. Hennink, Biomacromolecules, 2008, 9, 158.

147 Q. Wang, L. Wang, M. S. Detamore and C. Berkland, Adv. Mater., 2008, 20, 236.

148 A. S. Sarvestani, W. Xu, X. He and E. Jabbari, Polymer, 2007, 48, 7113.

149 C. Hiemstra, W. Zhou, Z. Zhong, M. Wouters and J. Feijen, J. Am. Chem. Soc., 2007, 129, 9918.

150 R. Censi, T. Vermonden, H. Deschout, K. Braeckmans, P. di Martino, S. C. De Smedt, C. F. van Nostrum and W. E. Hennink, Biomacromolecules, 2010, 11, 2143.

151 N. Sanabria-DeLong, A. J. Crosby and G. N. Tew, Biomacromolecules, 2008, 9, 2784.

152 A. Galperin, T. J. Long and B. D. Ratner, Biomacromolecules, 2010, 11, 2583.

153 J. D. Clapper, M. E. Pearce, C. A. Guymon and A. K. Salem, Biomacromolecules, 2008, 9, 1188.

154 R. A. Dwek, Chem. Rev., 1996, 96, 683.

155 E. K. Woller, E. D. Walter, J. R. Morgan, D. J. Singel and M. J. Cloninger, J. Am. Chem. Soc., 2003, 125, 8820.

156 M. Okada, Prog. Polym. Sci., 2001, 26, 67.

157 M. Hales, C. Barner-Kowollik, T. P. Davis and M. H. Stenzel, Langmuir, 2004, 20, 10809.

158 S. R. S. Ting, A. M. Gregory and M. H. Stenzel, Biomacromolecules, 2009, 10, 342.

159 L. Forciniti, N. K. Guimard, S. Lee and C. E. Schmidt, J. Mater. Chem., 2010, 20, 8865. 